\title{
An Analysis of ODL Student Perception and Adoption Behavior using the Technology Acceptance Model
}

Khor Ean Teng

Wawasan Open University, Malaysia

\section{Abstract}

This paper presents an empirical study aiming on investigating ODL students' perception and adoption of SCORM Compliant Learning Object (SCLO). With the increasing use of SCLO in recent years, a better understanding and implementation of effective instructional resources is necessary to meet the diverse needs of ODL students and enhance their learning performance. The eventual usage of relevant stakeholders determines the success of a system. The system is useless if it is not used in the expected way by the potential users even though it is a good system. Therefore, the aim of this research is to examine if ODL students will eventually use SCLO for their learning. The study used TAM as a basis to investigate the relationship of external and internal variables. A survey instrument eliciting responses on a series of Likert-type questions was given to selected ODL undergraduate students. The results of this study confirm that users' perception has significant effect on the acceptance and adoption of SCLO. The study provides a better understanding of students' behavior on SCLO and the acceptance model.

Keywords: SCORM; learning object; content quality; cognitive absorption; intrinsic motivation; perceived ease of use; perceived usefulness; attitude towards using; intention to use 


\section{Introduction}

Sharable Content Object Reference Model (SCORM) has become one of the important specifications of content packaging and platform development in open and distance learning (ODL). SCORM is created primarily for vendors and designers who build LMS and learning content authoring tools so that they conform to SCORM technically and the courseware content is designed to run on any SCORM-compliant LMSs. Standards such as SCORM allow reusable learning objects (RLOs) to be created and shared across the e-learning community.

SCLO is learning objects that have been meta-tagged for SCORM compliance. SCLO can be easily interoperated among different learning management systems (LMS) without being tied to a single content provider or authoring tool. The use of SCLO is increasingly prevalent in many e-Learning systems and higher educational institutions. This allows reuse of learning objects and helps with cost and time reduction. The same set of learning objects allows for different instructional design with individual learning objectives.

With the potential benefits of SCLO, there are questions raised on whether students will eventually adopt it for their learning. It is vital to understand the factors of information technology system usage in order to evaluate the effectiveness of system and develop solutions for user acceptance (Knight \& Pearson, 2005). In this regard, this research aims to understand and determine students' behavioural intentions to use SCLO using the technology acceptance model (TAM).

With the new delivery methods of e-learning systems, TAM can be used in predicting students' acceptance of IT or IS system. It has been found to be a generous and vigorous model in many e-learning studies (Cheung \& Huang, 2005; Drennan, Kennedy \& Pisarki, 2005; Liaw \& Huang, 2003).

\section{Literature Review and Research Model}

\section{Learning Objects}

There has been an increased usage of learning objects (LOs) in instructional technology (Anderson, 2003). Wiley (2000) defined LOs as any digital resource that can be reused to support learning. In other words, LOs are a self-contained and re-usable digital resource.

Several studies revealed good impact of learning objects for the effectiveness and efficiency of instructional design strategies. A study conducted by Van Zele et al. (2003) 
showed that students perceived to have learned more by using learning objects. Findings from a study conducted by Boyle (2003) also showed that there is positive acceptance of the learning object design. The finding of Cochrane's (2005) study also showed the learning objects have the potential to enhance learning for audio engineering. In addition, Bradley and Boyle's (2004) study found that learning objects have a significant impact in improving the teaching and learning process.

LOs have been integrated into several SCORM-compliant learning management systems (Moodle, Claroline, ATutor, and Docebo) due to their potential benefits.

\section{SCORM-compliant learning object.}

SCLO are learning objects that are able to communicate with a learning management system to record user scores, times, and progress (ADL, 2002). These are the most portable and reusable of learning objects as they will work with any SCORM-compliant learning management system. To ensure that the objects themselves are even more portable, SCORM recommends that several other rules be followed when developing the learning objects. Each learning object is a standalone entity. It does not rely on other learning objects to function, and does not specifically refer to other learning objects.

SCLO can be delivered in a runtime SCORM environment and meta-tagged to be stored in and retrieved from a knowledgebase according to different selection criteria. According to Carnegie Mellon (2004), the use of metadata allows identification and location of instructional material in a data repository.

\section{Behavioral Model}

The theory of reasoned action (TRA), the theory of planned behaviour (TPB), and the technology acceptance model (TAM) are the three intention based models that focus on the identification of determinants of intentions and the relationships of constructs and variables on innovation usage.

\section{The theory of reasoned action.}

TRA was developed by Fishbein and Ajzen (1975) to predict and investigate behavioural belief. As shown in Figure 1, the two psychological determinants, 'attitude towards behaviour' and 'subjective norm', determine intention, which in turn determine behavioural belief. 


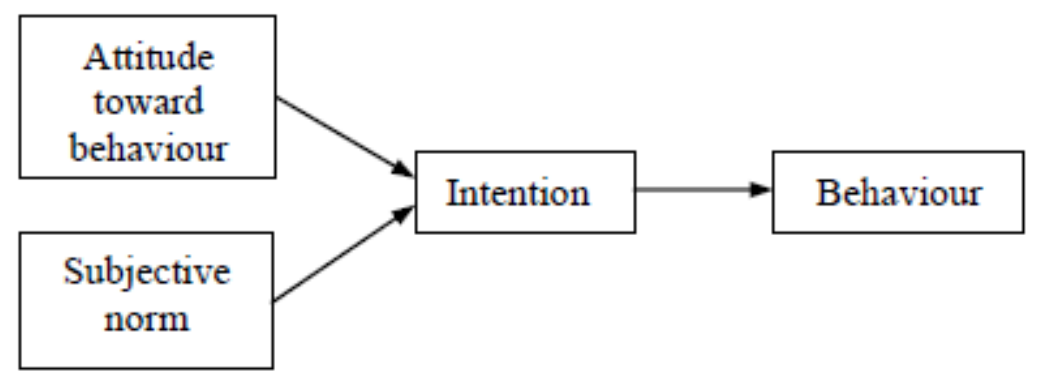

Figure 1. The theory of reasoned action (Fishbein \&Ajzen. 1975)

Fishbein and Ajzen (1975) defined attitude as an individual's degrees of evaluative effect towards a target behaviour. On the other hand, subjective norm means a person's beliefs that others think he or she should or should not perform the behaviour underlying normative belief (Ajzen \& Fishbein, 1980). Behavioural intention is defined as an individual's subjective probability that he or she will perform a specified behaviour (Fishbein \&Ajzen, 1975).

\section{The theory of planned behavior.}

TPB is an extension of TRA by adding a construct called perceived behavioural control. TPB proposes that three beliefs influence behavioural intentions, which influence behaviour.

As shown in Figure 2, individual behaviour is determined by behavioural intention, which is then determined by three psychological determinants. The three psychological determinants are 'Attitude towards Behaviour', 'Subjective Norm' and 'Perceived Behavioural Control'.

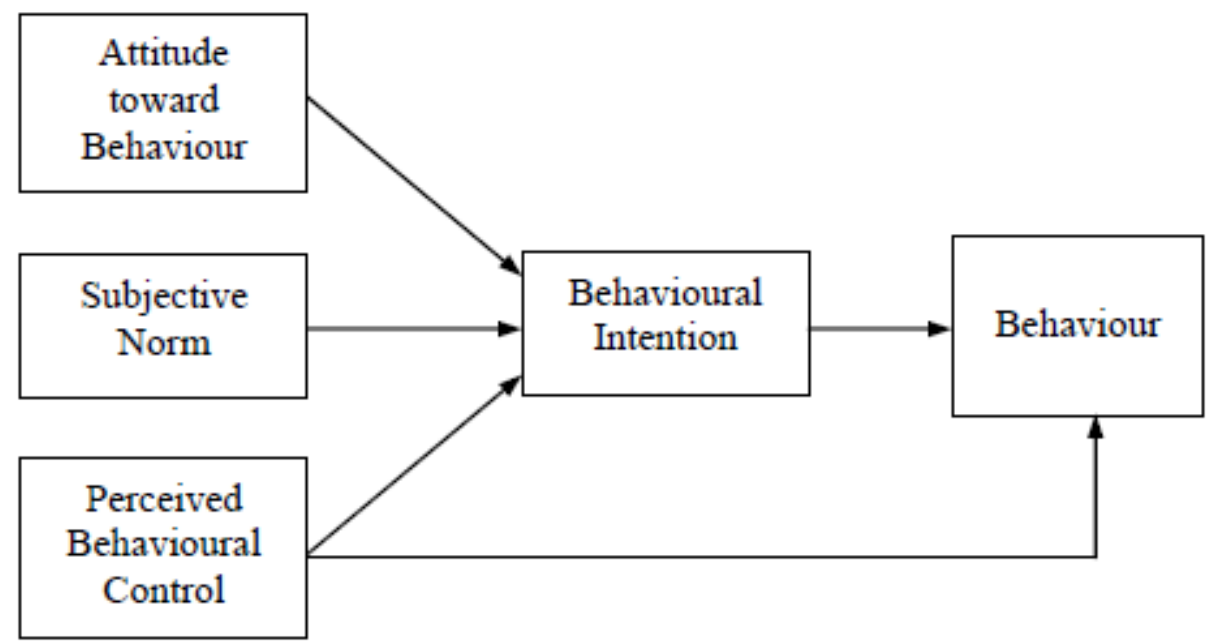

Figure 1. The theory of planned behavior (Ajzen, 1991). 


\section{Technology acceptance model.}

TAM was developed by Davis (1989) to investigate the reasons why people accept or reject an information technology. The TAM model was developed and derived based on TRA model. Figure 3 illustrates the TAM model as proposed by Davis (1989). Davis indicated that 'perceived ease of use' and 'perceived usefulness' are the two most important belief constructs of using information technology. These two beliefs lead to behaviour intention and actual behaviour

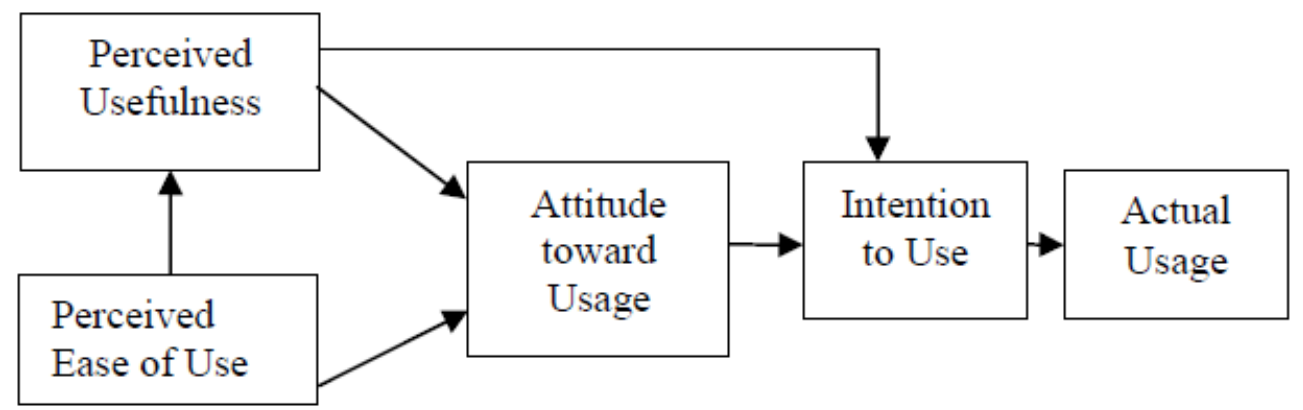

Figure 2. The technology acceptance model (Davis, 1989).

Based on relevant literature, the researcher decided to use an extended version of Davis's (1989) TAM as the survey instrument. The TAM is considered salient to the attitudes and behaviors studied. The TAM is also used because of its tested validity and reliability in measuring and predicting attitudes, technology acceptance, and use. On top of this, numerous studies have also included external variables to extend TAM in order to improve understanding ways individuals adopt information systems.

\section{Research Variables}

The three external variables (content quality, cognitive absorption, and intrinsic motivation) have been added to Davis's extended TAM model in this research study.

Content quality (CQ) can be defined as veracity, accuracy, balanced presentation of ideas, and appropriate level of detail (Nesbit, Belfer, \& Leacock, 2003). The construct is vital for the evaluation of digital content resources as suggested by previous studies (CLOE Peer Review, 2004; DLNET Guidelines, 2004; Wisc-Online Quality Standards, 2004).

Cognitive absorption (CA) is the antecedent of two key determinants in TAM, PU and PEOU. Agarwal and Karahanna (2000) argued that cognitive absorption is an underlying determinant of PEOU and PU.

Deci (1972) defined intrinsic motivation (IM) as the internal rewards which refer to the pleasure a person has while performing an activity. Lee, Cheung, and Chen (2005) suggested adding IM constructs to better explain IT adoption when they reviewed TAM. 


\section{Research Model and Hypotheses}

Figure 4 illustrates the research model used in this study.

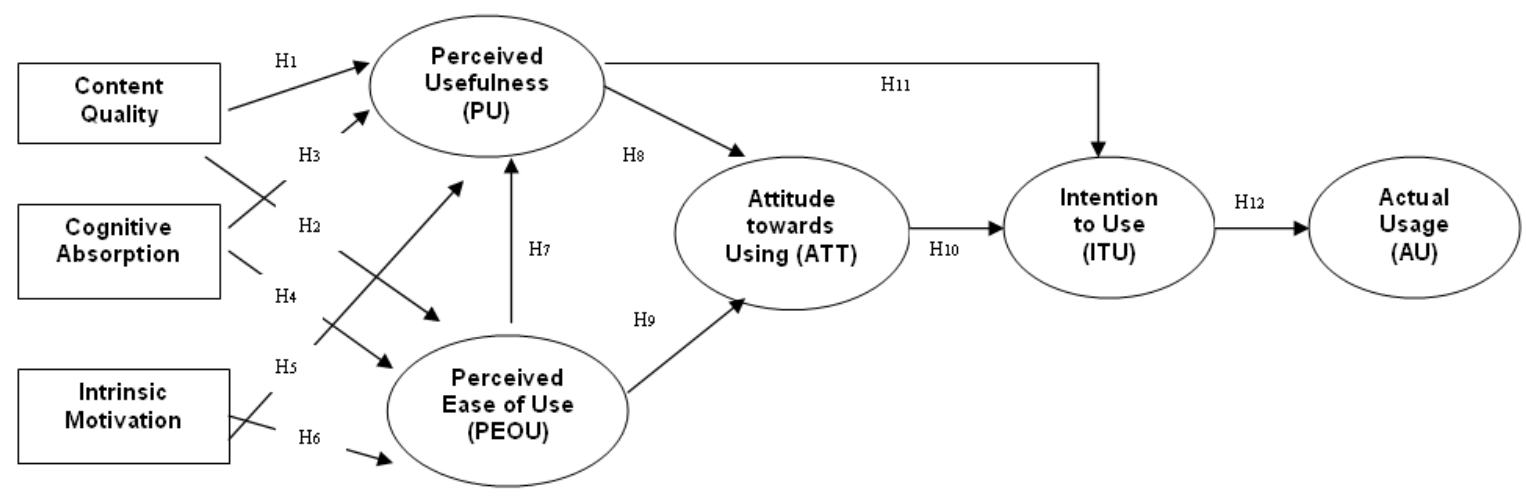

Figure 3. SCORM-compliant learning object acceptance model (SCLOAM).

The following hypotheses were proposed in this study:

H1: Content quality has significant effect on perceived usefulness.

H2: Content quality has significant effect on perceived ease of use.

H3: Cognitive absorption has significant effect on perceived usefulness.

H4: Cognitive absorption has significant effect on perceived ease of use.

H5: Intrinsic motivation has significant effect on perceived usefulness.

H6: Intrinsic motivation has significant effect on perceived ease of use.

H7: Perceived ease of use has significant effect on perceived usefulness.

H8: Perceived usefulness has significant effect on attitude towards using.

H9: Perceived ease of use has significant effect on attitude towards using.

H10: Attitude towards using has significant effect on intention to use.

H11: Perceived usefulness has significant effect on intention to use.

H12: Intention to use has significant effect on actual usage. 


\section{Research Methodology}

The participants were recruited from ODL students who enrolled in the Structured Programming course offered by Wawasan Open University (WOU) in Jan 2014 semester. Students were introduced to SCLO at the beginning of the semester. Training was provided to the students on the hands-on direct experience of using SCLO through LMS for additional learning support.

Students were then invited to participate in the online survey on a voluntary basis at the 14th week of the semester for a period of two months. An email was sent to remind the participants one week before the closing of the survey.

The questionnaire included three items for content quality (CQ1-3), three items for cognitive absorption (CA1-3), three items for intrinsic motivation (IM1-3), four items for perceived ease of use (PEOU1-4), four items for perceived usefulness (PU1-4), three items for attitude (ATT1-3), three items for intention (ITU1-3), and three items for actual use (AU1-3). All items are measured five-point Likert scales anchored between "strongly disagree" and "strongly agree". Respondents were asked to provide basic demographic information and answer one open-ended question too.

Data processing was performed using the SPSS program, version 21. Description and inferential statistics were used to conduct the analysis. A series of regression analyses were conducted to observe the relationship between the constructs.

\section{Data Analysis and Results}

Out of 90 questionnaires collected, 12 cases were removed due to incomplete information. The response rate was $87 \%$.

The SPSS program was used to conduct statistical tests to evaluate reliability and validity of the instrument. Instrument validation involves processes used to assess instrument reliability and validity. Reliability addresses the degree to which instruments measure consistently on different occasions, and, as Fiske (1971) describes, are free of variable error, and where measurement techniques are accurate and dependable (Cronbach, 1951). Validity addresses the degree of truthfulness and the extent of how generalizations are made.

All the constructs were assessed for reliability using Cronbach's coefficient alpha. The coefficient for all of the measures exhibited strong reliability, ranging from .848 to .976. Table 1 summarizes the result of reliability testing of each construct. 
Table 1

Reliability Coefficient for Individual Variables

\begin{tabular}{lcc}
\hline Construct & Items & Alpha \\
\hline Content quality (CQ) & 3 & .950 \\
Cognitive absorption (CA) & 3 & .874 \\
Intrinsic motivation (IM) & 3 & .903 \\
Perceived ease of use (PEOU) & 4 & .959 \\
Perceived usefulness (PU) & 4 & .976 \\
Attitude towards using(ATT) & 3 & .848 \\
Intention to use (ITU) & 3 & .933 \\
Actual usage (AU) & 3 & .925 \\
\hline
\end{tabular}

To get satisfactory discriminant validity, the square root of average variance extracted (AVE) for each construct should be greater than the correlation between the construct and the other constructs. Table 2 shows acceptable discriminant validity between each pair of constructs, with all AVE square roots greater than the correlation between the constructs.

Table 2

AVE Square Roots and Inter-Correlation

\begin{tabular}{lcccccccc}
\hline Construct & CQ & CA & IM & PEOU & PU & ATT & ITU & AU \\
\hline CQ & 1.000 & & & & & & & \\
CA & $.827^{* *}$ & 1.000 & & & & & & \\
IM & $.971^{* *}$ & $.880^{* *}$ & 1.000 & & & & & \\
PEOU & $.960^{* *}$ & $.825^{* *}$ & $.950^{* *}$ & 1.000 & & & & \\
PU & $.952^{* *}$ & $.800^{* *}$ & $.914^{* *}$ & $.947^{* *}$ & 1.000 & & & \\
ATT & $.896^{* *}$ & $.791^{* *}$ & $.872^{* *}$ & $.885^{* *}$ & $.868^{* *}$ & 1.000 & & \\
ITU & $.913^{* *}$ & $.844^{* *}$ & $.906^{* *}$ & $.914^{* *}$ & $.924^{* *}$ & $.870^{* *}$ & 1.000 & \\
AU & $.959^{* *}$ & $.827^{* *}$ & $.932^{* *}$ & $.981^{* *}$ & $.964^{* *}$ & $.873^{* *}$ & $.934^{* *}$ & 1.000 \\
\hline
\end{tabular}

$* *$ Correlation is significant at the .01 level (2-tailed) 
In this study, mean and standard deviation are used to describe the statistics. As observed from Table 3, all the mean values fall above the midpoint. The standard deviations range from .678 to 1.021 . This indicates that most of the respondents are between "agree" to "strongly agree" on the items tested.

Table 3

Mean and Standard Deviation of Each Variable

\begin{tabular}{lcc}
\hline Construct & MEAN & SD \\
\hline CQ & 3.501 & .973 \\
CA & 3.857 & .678 \\
IM & 3.563 & .799 \\
PEOU & 3.490 & .990 \\
PU & 3.540 & 1.021 \\
ATT & 3.870 & .749 \\
ITU & 3.547 & .928 \\
AU & 3.530 & .968 \\
\hline
\end{tabular}

Table 4 summarizes the results from the regression analysis. The analyses of the regression equations revealed that the $\mathrm{R}^{2}$ and $\beta$ can be used to predict the values of the dependent variable based on the values of the independent variable. Both $\mathrm{R}^{2}$ and $\beta$ values show how well the data support the hypothesised model. From the findings, it shows that demographic variables had no significant effect on dependent variables.

Table 4

Regression Analysis Result Summary

\begin{tabular}{lcccccc}
\hline $\begin{array}{c}\text { Dependent } \\
\text { variables }\end{array}$ & $\mathrm{R}^{2}$ & $\begin{array}{c}\text { Independent } \\
\text { variables }\end{array}$ & $\beta$ & $\begin{array}{c}\text { Standard } \\
\text { error of } \beta\end{array}$ & $\mathrm{t}$ & $\mathrm{P}$ \\
\hline PEOU & .915 & CQ & .672 & .149 & 6.119 & $<001$ \\
& & CA & .029 & .107 & .519 & $>.05$ \\
PU & .928 & IM & .272 & .215 & 2.098 & $<05$ \\
& & CQ & .852 & .178 & 6.770 & $<001$ \\
& & CA & .109 & .111 & 1.961 & $<001$ \\
& & IM & -.480 & .226 & -3.618 & $>.05$ \\
ATT & .792 & PEOU & .495 & .098 & 5.212 & $<001$ \\
& & PEOU & .611 & .076 & 4.549 & $<001$ \\
ITU & .873 & PU & .289 & .074 & 2.152 & $<05$ \\
& & PU & .684 & .046 & 10.083 & $<001$ \\
AU & .872 & ATT & .276 & .084 & 4.075 & $<001$ \\
& & ITU & .934 & .035 & 27.749 & $<001$ \\
\hline
\end{tabular}


The resulting path diagram is presented in Figure 5. Overall, the whole model was able to account for $87.2 \%$ of variance in the construct of AU. CQ, CA and IM had significant direct and indirect positive effect on PEOU and PU. PEOU had significant direct positive effect on PU. PU had significant direct positive effect on ATT and ITU. ITU had significant effect on AU. The results show most of the proposed hypotheses were supported (Table 5).

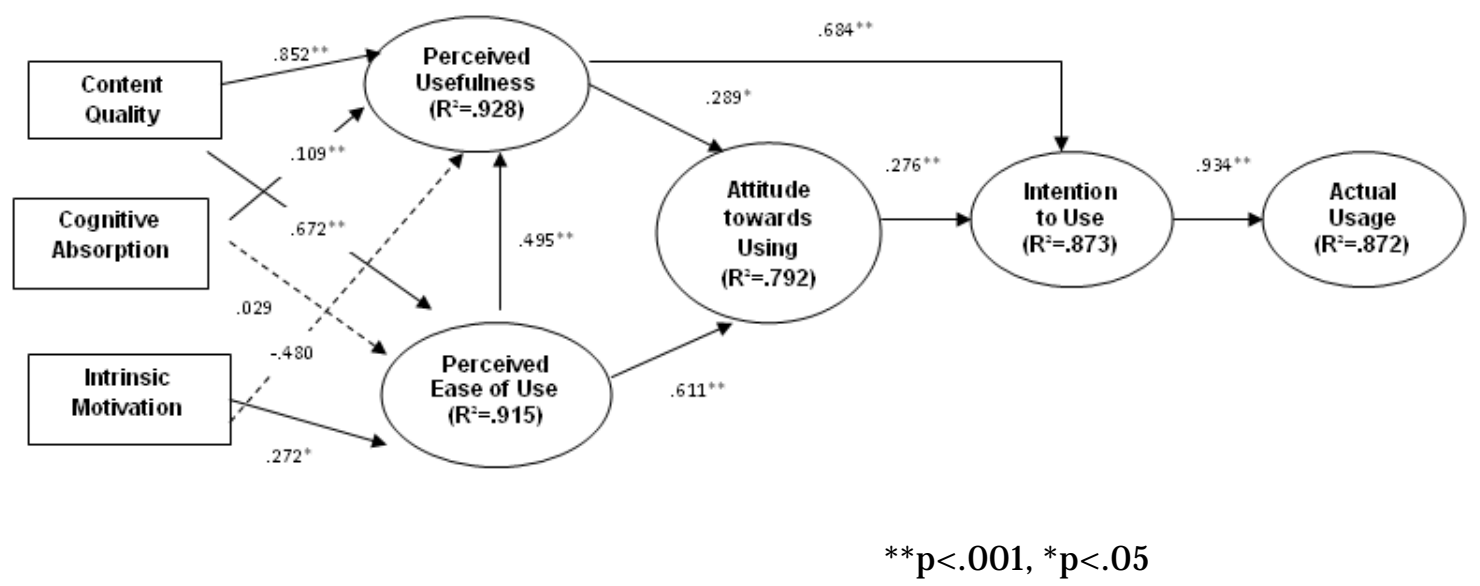

Figure 4. Final conceptual research model.

Table 5

Hypothesis Testing Results

Hypothesis

H1: Content quality has significant effect on perceived usefulness.

H2: Content quality has significant effect on perceived ease of use.

H3: Cognitive absorption has significant effect on perceived usefulness.

H4: Cognitive absorption has significant effect on perceived ease of use.

H5: Intrinsic motivation has significant effect on perceived usefulness.

H6: Intrinsic motivation has significant effect on perceived ease of use.

H7: Perceived ease of use has significant effect on perceived usefulness.

H8: Perceived usefulness has significant effect on attitude towards using.

H9: Perceived ease of use has significant effect on attitude towards using.

H10: Attitude towards using has significant effect on intention to use.

H11: Perceived usefulness has significant effect on intention to use.

H12: Intention to use has significant effect on actual usage.
Result

Supported

Supported

Supported

Not Supported

Not Supported

Supported

Supported

Supported

Supported

Supported

Supported

Supported 
Table 6 shows the samples of qualitative data collected from the open-ended question. The open-ended question basically asked the respondents what they thought about SCLO. It was an optional question.

Table 6

Students' Response to Open-Ended Questions

\begin{tabular}{|l|l|}
\hline$\#$ & Examples of students' open-ended question responses \\
\hline 6 & "It is a great learning support definitely" \\
\hline 19 & $\begin{array}{l}\text { "It takes some time to load some of SCLO which have heavy multimedia } \\
\text { elements" }\end{array}$ \\
\hline 27 & "I will continue to adopt SCLO in my studies" \\
\hline 31 & "easy to use, I am able to use without additional training" \\
\hline 37 & "I can easily move to other topics and go backward with SCLO " \\
\hline 43 & "some content are too lengthy, point form would be good" \\
\hline 57 & "I used SCLO for my revision" \\
\hline 64 & "It would be good if there is audio feature" \\
\hline 73 & "need higher bandwidth to ease the access" \\
\hline 78 & "I have no problem to use SCLO" \\
\hline 83 & "The learning activities are very useful and helpful for me" \\
\hline 90 & "SCLO really helps me to understand the content better" \\
\hline 94 & "I personally feel this learning aid is better than the others" \\
\hline
\end{tabular}

\section{Conclusions}

The purpose of this research paper was to understand and predict ODL students' acceptance of SCLO by hypothesising the relationships between variables that affect students' adoption behavior. Results of the regression analyses show that the true usage an individual makes of a system is driven by the ITU, which in turn is determined by ATT, PU, PEOU, CQ, CA, and IM. This study demonstrated that the constructs of SCLOAM are viable resources for analyzing ODL students' perceptions towards the use of SCLO for their learning. This research also provides new insight on the evaluation and prediction of technology acceptability. The findings help relevant stakeholders to enhance their existing learning systems by integrating appropriate learning theories. The findings can be referenced as guidelines to increase the use of particular systems. In addition, they can widen the applicability of TAM in the education field, especially in the context of SCLO. There are other variables that could be studied in this study. Therefore, further exploration of other possible constructs like computer self-efficacy is suggested. 


\section{References}

ADL. (2002). Advanced Distributed Learning Initiative. Sharable Courseware Object Reference Model (SCORM). Retrieved J uly 25, 2013, from http:// www.adlnet.org/Scorm/dpwnloads.cfm

Ajzen, I. (1991). The theory of planned behavior, organizational behavior and human decision processes. 50(2), 179-211.

Ajzen, I., \& Fishbein, M. (1980). Understanding attitudes and predicting social behaviour. Englewood Cliffs, NewJ ersey: Prentice-Hall.

Agarwal, R., \&Karahanna, E. (2000). Time flies when you're having fun: Cognitive absorption and beliefs about information technology usage. MIS Quarterly, 24(4), 665-694.

Anderson, T. A. (2003). I object! Moving beyond learning objects to learning components. Educational Technology, 43(4), 19-24.

Boyle, T. (2003). Design principles for authoring dynamic, reusable learning objects. Australian J ournal of Educational Technology, 19(1), 46-58.

Bradley, C., \& Boyle, T. (2004). Students' use of learning objects. Retrieved 18, May 2013, from http://imej.wfu.edu/articles/2004/2/01/index.asp

Bruner, G. C., \& Kumar, A. (2005). Explaining consumer acceptance of handheld Internet devices. J ournal of Business Research, 58(5), 553- 558.

Carnegie Mellon. (2004). Learning Systems Architecture Lab. Best practices guide for content developers (1 ${ }^{\text {st }}$ ed., including updates to Section 7). Retrieved Aug 15, from http:// www.lsal.cmu.edu/lsal/ expertise/ projects/developersguide/ i

Cheung, E., \&Huang, W. (2005). Proposing a framework to assess internet usage in university education: An empirical investigating from a student's perspective. British J ournal of Educational, 36(2), 237-253.

CLOE Peer Review. (2004). Peer Review Evaluation Standards. Retrieved May 28, 2013, from http://cloe.on.ca/ peerreview.html

Cochrane, T. (2005). Interactive QuickTime: Developing and evaluating multimedia learning objects to enhance both face-to-face and distance e-learning environments. Interdisciplinary J ournal of Knowledge and Learning Objects, 1(1), 33-54.

Cronbach, L. (1951). Coefficient alpha and the internal structure test. Psychometrika, 16(3), 297-333. 
Davis, F. D. (1986). A technology acceptance model for empirically testing new enduser information systems: Theory and results (Doctoral dissertation). Cambridge-MA: MIT, Sloan School of Management.

Davis, F. D. (1989). Perceived usefulness, perceived ease of use, and user acceptance of information technology. MIS Quarterly, 13(3), 319- 339.

Deci, E. L. (1972). Intrinsic motivation, extrinsic reinforcement and inequity. J ournal of Personality and Social Psychology, 22(1), 113-120.

DLNET Guidelines. (2004). DLNET Guidelines for the Reviewer. Retrieved J une 10, 2013, from http:// www.dlnet.vt.edu/ ReviewerGuidelines.jsp\#review_form

Drennan, J ., Kennedy, J ., \& Pisarksi, A. (2005). Factors affecting student attitudes toward flexible online learning in management education. The J ournal of Educational Research, 98(6), 331-340.

Fishbein, M., \&Ajzen, I. (1975). Beliefs, attitude, intention and behavior: An introduction to theory and research. Boston: Addison-Wesley.

Fiske, D. (1971). Measuring the concepts of personality. Chicago. Aldine Publishing Company.

Liaw, S. S., \& Huang, H. M. (2003). An investigation of user attitudes toward search engines as an information retrieval tool. Computers in Human Behaviour, 19(6), 751-765.

Lee, M. K., Cheung, C. M., \& Chen, Z. (2005). Acceptance of internet-based learning medium: The role of extrinsic and intrinsic motivation. Information \& Management, 42(8), 1095 -1104.

Nesbit, J . C., Belfer, K., \& Leacock, T. (2003). Learning object review instrument (LORI). Retrieved May 10, 2013, from http:// www.elera.net

Nunnally, J .(1967). Psychometric theory. NewYork: McGraw-Hill.

Saadé, R.-G., Nebebe, F., \&Tan, W. (2007). Viability of the technology acceptance model in multimedia learning environments: A comparative study. Interdisciplinary J ournal of E-Learning and Learning Objects, 3(1), 175-184.

Van Zele, E., Vandaele, P., Bottledooren, D., \&Lenaerts, J . (2003). Implementation and evaluation of a course concept based on reusable learning objects. J ournal of Computing Research, 28(4), 355-372.

Wiley, D. A. (2000). Learning object design and sequencing theory (Doctoral thesis). Brigham Young University. 
Wisc-Online Quality Standards. (2004). Wisc-Online Quality Standards. Retrieved May 17, 2013, from http:// www.wisc-

online.com/members/ resources/QualityStandards.asp

(C) Khor

\section{Athabasca University}

(c) (7)

This work is licensed under a Creative Commons Attribution 4.0 International License 